\title{
* POPULAR MISCONCEPTIONS OF LEPROSY
}

\author{
G. A. Ryrie.
}

I was sitting in my office one afternoon about a year ago when two Chinese youths appeared at the entrance. The effect was a little startling at first, for the pair were as far as I could see duplicates of each other. They were in fact what is called identical twins aged about 20 and introduced themselves. They were afraid they had got leprosy and had come down from Ipoh to be examined. Curiously enough even the marks of their disease were roughly similar in size and over roughly the same area of the body.

Telling people they have got leprosy is one of the most unpleasant jobs I know and custom does not make it any easier. In the case of educated Chinese it is somehow easier to tell the man as shortly as possible that he has got leprosy and then ask him to come back and see you in an hour's time. By the end of an hour he has recovered from the shock, has thought it all out in his own way and is ready to discuss the next steps.

I told them as gently as I could that they had got it and suggested that they might go for a walk and talk it over between themselves. When they returned I waited for them to speak, for long experience has taught me that it is better to let them question me. Otherwise you may be trying to comfort the patient about problems that his mind has not worked round to yet. You may start telling him about treatment when all the time he is worrying about whether he has to pay for his food in the Settlement or whether he can use a false name to avoid his friends being implicated.

I told one of them that in less than two years with ordinary luck he should be back at his job again.

I could not tell the other what I knew-that long after his brother was well and fit he would still be in Sungei Buloh. Indeed from where he stood near my office I could have pointed out the hill side where he would be buried some day. He did not know that then, he does not know it now.

They are illustrations of a fact that we have only begun to realise properly in recent years, that there are at least two different kinds of leprosy. People knew vaguely before that there were different kinds of leprosy, but until recently it did not seem of much importance.

In the Philippines, however, a great deal of work has been

* Address delivered at the Kuala Lumpur Fortnightly Club. Reprinted from the Malay Mail, April 29th, 1938. 
done to ascertain the exact nature of the differences. In Malaya we concentrated rather on the difference in their response to treatment and what was the best that we could do for each. We know now definitely that there are two main groups.

In one group treatment is much more effective than most people realise. We can in practically all the cases promise definite improvement. If they come in at any reasonable stage at all we can usually promise to clear those of any active signs of the disease.

Last year I had an old Chinese brought to me. He had had slowly spreading leprosy for 27 years and it had literally covered half of his body. The part affected was completely numb, with all the sweat glands paralysed. That is to say that when he sat in the sun one half of his body did not sweat and so became hot just like the bonnet of your car. The other half remained normal. Between these two areas was a great red bar like a bandolier running diagonally round the body. To-day after one year's treatment we have practically wiped away the 27 years accumulation of leprosy.

The other kind, unfortunately, is not yet nearly so responsive to treatment and in its worst phases seems to go on and on in spite of anything we can do. One man was lucky, he belonged to the benign type. His brother was unlucky; he had picked on the malignant variety-the old, old story of the one shall be taken and the other left.

It is, however, important that the public should know about this. The benign type are not of very much danger to the public, and the treatment is so effective that they could be dealt with in ordinary hospitals and outdoor dispensaries. This would free a large part of the leprosy world from the shame and horror of being dragged away from their families. So that the time may and undoubtedly will come when we shall see lepers in the streets again-not as in the old days through neglect, but because they have been recognised as having a special type of leprosy that we can control with relative ease and which does not seem to be infective. The benign type is thus doubly lucky-he need not be shut up and he can get a cure.

Leprosy is usually considered a rare disease, in fact I find that many people in England believe that leprosy is now extinct like the Dodo. It is partly due to a curious assumption at Home that nothing in the Bible is true now. During the Great War numbers of people were surprised to find that Jerusalem was a real place; they thought it was only in the Bible. So with leprosy. It was mentioned in the Bible and, therefore, can have no relation to anything real now. As a matter of fact at the present day leprosy is by no means a rare disease. 
One in every 500 of the whole world's population-not Malaya-but the whole world's population is a leper. That is a very conservative figure-a Netherlands authority places it as one leper for every 380 people in the world.

Out of all the lepers perhaps one out of 50 is being cared for and not one in five hundred is being cared for as lepers ought to be.

This becomes very understandable if you consider the history of medical progress to find what a hopelessly brainless creature the human animal is when it comes to protecting him from disease. Clean water supplies, protection against typhoid and smallpox, infant welfare, maternity care, have all had to come to their own against determined opposition.

In England this year literally hundreds of children will die of diphtheria. Death from diphtheria is a grim and unpleasant way for a child to die and it is a grim and unpleasant thing to watch. Almost all these deaths are unnecessary and they could be stopped in a few months. But we do not do it.

As far as leprosy is concerned the world is not prepared to spend more than enough to give a certain amount of care to about one leper out of 50 . The money spent on cosmetics in England, the U.S.A., would provide comfortably for every leper in the world. A stoppage of England's armament programme for two hours would provide food, clothing, care and treatment for all the lepers in the F.M.S. till I965. Again a fraction of the money spent on tobacco, sweets or alcohol would provide for all the lepers in the world. In this respect the human race is very much like the millionaire who rides his Rolls Royce and smokes his big cigar, but cannot afford the money to get rid of a boil on the back of his neck.

There are more misconceptions about leprosy than about any other disease of which I know. One of the commonest is still the idea that leprosy is highly infectious.

Leprosy is, of course, speaking broadly neither infectious nor contagious in the ordinary sense of these words.

I can recall some interesting examples of the belief. I remember getting a bill from a Chinese detective who had escorted a leper to Sungei Buloh. He went home and burnt all his clothes and sent me the bill for his new suit.

There are three things we know about infection. One is that small children staying with lepers tend to develop leprosy. If we left lepers alone and instead took all their children away we might be able to stamp out leprosy much quicker than at present. A second thing is that it is extremely difficult for an ordinary adult to get leprosy even if he tries. People have tried and 
scientists have inoculated themselves with the microbe of the disease and nothing has happened.

We may take it then that contact with leprosy even to the extent of germs being driven into the body has very little chance of infecting the ordinary adult.

Marriage with a leper rarely causes the other partner to get leprosy. Children are not born with leprosy; they contract it usually between the age of 5-Io. If it were the sins of their parents it would shew at birth. And if anybody can see the hundred little children at Sungei Buloh and suggest that these happy smiling kiddies are a crowd of debauched young roues, then I can only say he is mad-hopelessly and incurably mad.

Lepers do not belong to any special class of people. They are an even slice out of the community. There is the wealthy towkay and the indigent rikisha puller; there is the schoolboy and the student and the teacher; there is the good honest tukan and the office kram; the tin miner, the rubber tapper and the Government servant. Most Government departments have a representative of one kind or another in Sungei Buloh-and most of the larger firms in Malaya.

It is a common belief that when a man gets leprosy his fingers and toes and nose and ears all drop off. It always summons up to my mind a vivid picture of attendants going round in the morning shovelling up the scattered ears and fingers and other appendages that have dropped off during the night.

Take the reality in contrast. Two different Government departments have sent me office clerks for treatment. They were not boarded out and when their months of sick leave were exhausted they returned to their jobs. One of these had a slight relapse and he was given another month's leave and is back in the office again. No one could possibly tell there had been anything wrong with these young men. So far as I am aware their ears and noses are still making the grade.

Now there are one or two things about Sungei Buloh that I think everyone with interest in Malaya ought to know. Sungei Buloh contains over two thousand patients and it is the largest leper hospital in the British Empire and it is the second largest in the world. As compared with other places, where different kinds of research, propaganda and survey work are carried on, Sungei Buloh is primarily a treatment centre, where experiments are constantly going on to improve our medical methods. Sungei Buloh aims also at providing a standard of nursing and comfort for the sick which is above that recognised anywhere else or ever has been recognised in the past. My job as I see it is not administrative nor in the scientific study of the chemistry and 
culture of leprosy, but in treating lepers and learning from the results how to treat them still better. This is, of course, work that only a doctor and the staff can do. But there are two other things that Sungei Buloh tries to do that concern the public. To explain let me go back a little.

One day about 8 years ago I drove up to Sungei Buloh on transfer from Perak as Medical Superintendent.

I arrived at midday and in the atternoon went along to see what the place was like. There was disease, of course-leprosy in great open sores, but there were other things-scabies, ringworm, parasites, bruises from fighting-all the marks of degradation. Everywhere I saw the same look, sullen hopeless shamed outcast look out of deformed faces. I he look haunted me and I had seen it before somewhere. And then I got it. It was at an internment camp during the war for I8-year-old soldier boys who had been found in the trenches with self-inflicted wounds. They stared out from behind the barbed wire at us marching past with the same beaten, shamefaced, hunted look. They said nothing and did not even shout for a fag. I had forgotten that look, but it came back to me then and I saw what was wrong with Sungei Buloh. Not'the filth nor the sores nor the dirty torn clothes. These were easy. There was something more difficult. Here in Sungei Buloh were seven hundred people, leaderless, broken spirited people without morale, who knew they were scum and that there was a great gulf between them and all normal people. And that fine afternoon the memory of those eighteen-year-old soldiers with self-inflicted wounds gave me the clue to Sungei Buloh. My lepers had to do things to get back their self-respect and to get back a sense of normality. They would have to be led, for they could not do it themselves.

What I realised that first afternoon is still true. Much, of course, has been done. There was a time when never a day passed without me hearing the phrase Ini macham sakit mati tidapa. Now I never hear it. But every patient who is admitted into Sungei Buloh has to be rehabilitated, has to have his selfrespect built up again. You must remember what a hell he has been through. Almost every leper who is able to think has thought of suicide. Hundreds of my patients have sat up at night staring into the darkness overwhelmed by a sense of horror.

Sungei Buloh exists, as I see it, and as I intend to have it, to give these men back their manhood. And that is where you can help. You can give me your old clothes-clothes are a big factor in restoring self-respect. You can give me gramophone records, toys, games, tennis balls, shuttlecocks, jersies, picture magazines. Ask your krani to send Chinese and Indian magazines 
too. If you are going on leave and want to send stuff do not leave the packing of it to the boy. I once got a parcel consisting of five broken stengah glasses and a 1926 John Little catalogue. People ought to do more of that than they do. Every leper suffers from psychic mutilation from a crushed personality, from a sense of degradation. They are proud to feel that they are not being shunned. In the wards you will find English speaking dressers who will be proud to show you things. You will see nothing horrible and you will, if you have an eye for these things, see much that is fine. And you will have done a little bit towards making them feel that they are not regarded with loathing. I have heard that some people imagine that it would not be right to be seen sight-seeing or patronising among these poor people. Such people cannot understand what a leper suffers from. Such people forget that it is we who have made the leper what he is by shunning him and regarding him with horror by our use of the word leper as a symbol of all that is loathsome and decaying.

That is what you-the public-have done to him. I think it is up to you to come out to them very humbly and try to undo it. Get to know some of them and make them a visit from time to time. If you cannot come out-if you are transferred send them a letter. Bring them money and please do not tell them how sorry you are for them-both of these will accentuate their sense of inferiority which I am trying to break. Those who have visited Sungei Buloh can assure you that my patients are delighted to see you.

My other great problem which you can help me with besides getting back their self-respect is to get back their sense of normality-the two things are allied but not the same. There are little children there who live in a land of disfigurement and injections and iodine and bandages-they know no other world. For 50 cents a head one can take a hundred children to a deserted bit of sea shore and give them a whole day of perfect bathing, mud-slinging and gorging. There are no arrangements to be made, no buying or fixing transport. They just need one or two people to stand by them in their fear of the outside world. Toys and pictures, books and puzzles are useful to the children too.

Then there are the old and crippled to be encouraged and it is in this that you can see some of the finest examples of human courage that I have ever seen. You must remember that the crippled and mutilated ones know that there is literally no hope. Were a cure to come to-morrow with a triumphant exit from the Settlement, these would still remain to hobble round the deserted houses waiting for the day when their mutilated bones find rest on the hillsides opposite. Can you expect them to be normal? 
It seems like asking too much-cut off from relations and friends, having leprosy, hands and feet twisted and numb, with nothing but death to look forward to. Think what it means for a woman to tell me that she cannot keep a mirror in her house because it makes her cry. If people like that threw in the sponge it would not be for us to judge. If they stick it out grimly we should admire them. What do they do? This is what they do.

I know a woman who has no hands and no teeth. She sews. I am not a judge of sewing so I don't know if it is good. She holds the needle between the stumps of her wrists and pulls it through with her lips. I' know an old Chinese with no hands. He has two old milk tins with a hole through the bottom of each and a length of string tied between. On the middle of the string is a piece of cloth and he washes by dipping his stumps into the milk tins and slinging the cloth over his back. I have a typist with no fingers and no toes. I know it sounds impossible but it is true. He types with his knuckles and a very remarkable sight it is-just like a miniature boxing match. He does not get paid. Its just that he completely refuses to be on the scrap heap. These people make me wonder sometimes. There is no animal that will stand up to a paralysing mutilation-physical courage will not take you that far. It makes one wonder sometimes what it is these men and women have got that not merely faces their disease but soars right above it. In the course of my life I have seen a good deal of physical bravery in the face of pain and I have ceased to be sentimental or easily impressed.

What these men and women have got is something more, something that should be spelt with a capital S. These are people the world shuns; they are people I am very proud to have met. One day we will find the means to prevent men and women and small children having to face the long and deep cruelty of advanced leprosy. Until that day comes I hope that some of you will try to help them with your understanding, your good will, your visits, your friendships and your gifts. I am not offering you a duty or a task, I am offering you a privilege and I hope that you and the outside public will take it. 